HEARES 01668

\title{
First appearance and development of motile properties in outer hair cells isolated from guinea-pig cochlea
}

\author{
Rémy Pujol ${ }^{1,2}$, Gary Zajic ${ }^{1}$, Didier Dulon ${ }^{1,3}$, Yoash Raphael ${ }^{1}$, Richard A. Altschuler ${ }^{1}$ \\ and Jochen Schacht ${ }^{1}$ \\ ${ }^{\prime}$ Kresge Hearing Research Institute, University of Michigan, Ann Arbor, Michigan, U.S.A. and ${ }^{2}$ INSERM U-254, Hôpital St. Charles, Montpellier, \\ ${ }^{3}$ INSERM U-229, Hôpital Pellegrin, Bordeaux, France
}

(Received 16 April 1991; accepted 7 August 1991)

\begin{abstract}
Cochleae from fetal guinea-pigs ( 37 to 64 gestation days, gd) were used to correlate the appearance of motile properties of isolated outer hair cells (OHCs) with the development of specific morphological features. Both the 'fast' electrically-driven and the 'slow' calcium-induced motilities appeared first in OHCs from basal turn of $52 \mathrm{gd}$ fetuses. At $56 \mathrm{gd}$, most of basal and some apical OHCs responded positively to both types of stimulation. $\Lambda \mathrm{ll}$ tested cells were positive at $64 \mathrm{gd}$. It is noteworthy that this period closcly corrcsponds to the onset and maturation of the gross cochlear potentials. Some structural changes in the organ of Corti may be correlated with the development of OHC motile properties: the acquisition of an adult-like cylindrical shape by the $\mathrm{OHC}$, its lateral detachment from neighboring Deiters cells, and its surrounding by fluid spaces. At the ultrastructural level, the formation of a first layer of laminated cisternae regularly aligned along the $\mathrm{OHC}$ plasma membrane from the cuticular plate down to the nuclear level, temporally coincided with the onset of in vitro motility (52 gd). The following days, pillars and a sub-membrane lattice were clearly noticed between the outermost cisternal memhrane and the plasma membrane. The results support the ideas that: motile properties observed in vitro reflect the in vivo active mechanisms, and that one single layer of laminated cisternae and its associated sub-plasma membrane material may be needed for $\mathrm{OHC}$ motility.
\end{abstract}

Cochlear development; Outer hair cell motilities; Outer hair cell ultrastructure

\section{Introduction}

In contrast to inner hair cells (IHCs), outer hair cells (OHCs) are now considered to be more than conventional mechanoreceptors. They are responsible for an active bio-mechanical process which feeds energy back into the cochlear partition, giving the cochlea its properties of high sensitivity and frequency selectivity. With the demonstration of electromotility in isolated guinea-pig OHCs (Brownell, 1984; Browncll et al., 1985), many models for the active bio-mechanical process have been proposed with the motile response of $\mathrm{OHC}$ to an exciting sound stimulus as a major factor. To date, the motile properties of OHCs, while indirectly supported by oto-acoustic emissions (Kemp, 1978), have only been documented in vitro. Two types of different mechanisms can be distinguished: respectively the so-called 'fast' and 'slow' motilities. Brownell (Brownell, 1984; Brownell et al., 1985) demonstrated that isolated OHCs contracted or elongated with electrical stimulation. This electromotility, not dependent on metabolic energy, is able to elicit forces at relatively

Correspondence to: R. Pujol, INSERM U-254, Hôpital St. Charles, 34059 Montpellier, Cedex 1, France. high frequencies (Kachar et al., 1986; Ashmore, 1987). On the other hand, the in vitro demonstration of a calcium-dependent slow OHC motility in detergentpermeabilized (Zenner et al., 1985) or intact cells (Dulon et al., 1990) may reflect an in vivo property of OHCs, namely their ability to modulate the cochlear mechanics under efferent neural control. Thus, the OHC response to a sound may consist of a unique double-transduction process: 1) the classical mechanoelectro transduction through membrane depolarization after a mechanical opening of ion channels, and 2) a reverse electro-mechano transduction through the fast OHC motility depending on changes of membrane potential. Superimposed on, the central nervous system may modulate the reverse electro-mechano transduction via efferent control of slow OHC motility (see recent reviews: Santos-Sacchi, 1988; Pujol, 1989).

One way to examine the role of OHCs is to correlate their development and the development of fine tuning with the developmental onset of the motile responses. During ontogeny, OHCs have been found to develop in a completely different way than IHCs (Pujol et al., 1978; Pujol, 1986). Their shape, innervation pattern, and arrangement with surrounding support cells, all change drastically during maturation. These drastic $\mathrm{OHC}$ changes coincide with the acquisition by 
the cochlea of its adult-like physiological properties (Pujol et al., 1980). Roughly, the maturation of the cochlea, starting from the onset of function, could be divided in two stages: 1) a primitive stage where both types of receptors (IHCs and OHCs) look similar, and where the coding of sensitivity and frequency is crude, and 2) a stage when OHCs evolve towards a completely different type of cell, gradually giving the cochlea its fine sensitivity and tuning. It is tempting to correlate these profound $\mathrm{OHC}$ changes with a late development of their specific motile properties (Pujol, 1986, 1989). Indeed, the late appearance and maturation of otoacoustic emissions (Lenoir and Puel, 1987; Norton et al., 1989) support this idea. However, to date, a direct approach of $\mathrm{OHC}$ motility during development is lacking.

In the present experiments we used developing guined-pigs, from gestational age (gd) 37 days till birth, to determine the time of appearance and development of motile propertics in isolated OHCs and to correlate it with ultrastructural and molecular features in the maturing OHCs. The guinea-pig was chosen for this study since most of the data on both the electrical (Brownell, 1984; Brownell et al., 1985; Zenner et al., 1987) and calcium-induced motility (Zenner et al., 1985; Dulon et al., 1990) were obtained on isolated guinea-pig OHCs. In addition, reports on structural (Thorn, 1975; Pujol and Hilding, 1973) and physiological (Romand, 1971; Romand et al., 1971; Pujol and Hilding, 1973) cochlear development in guinea-pigs allow a reliable correlation. Two types of motilities, electrically-driven and calcium-dependent respectively, were tested in one fetus from each litter. In addition, to help to discern the substrate of the motile responses, cochleae from littermates were prepared for clectron microscopy and immunocytochemistry. Some preliminary observations have been presented (Pujol et al., 1990a,b).

\section{Methods}

Fetuses from thirteen litters of albino guinea-pig varying in age between gestational days (gd) 37 and 64 as well as 2 newborn animals were investigated. The developmental age was assessed by comparing weight and length (crane-rump: cr) of fetuses, corrected by the number of littermates, with Draper's (Draper, 1920) tables (see Table I). Fetuses were taken by cesarian section, under ketamine/Rompun (2/3) anaesthesia of the mother. From each litter, cochleae of the first fetus were dissected for isolation of OHCs. Other fetuses were prepared for morphological and histochemical analyses.

\section{Hair cell preparation}

Hair cells were isolated from the fetal cochleae essentially as previously described in adult prepara-
I'ABLE I

LITTERS OF GUINEA-PIG FETUSES

\begin{tabular}{lllcc}
\hline $\begin{array}{l}\text { Age } \\
\text { of fetus } \\
\text { (gd) }\end{array}$ & $\begin{array}{l}\text { Number } \\
\text { of } \\
\text { litters }\end{array}$ & $\begin{array}{l}\text { N. fetuses } \\
\text { litter }\end{array}$ & $\begin{array}{l}\text { Mean } \\
\text { weight } \\
(\mathrm{g})\end{array}$ & $\begin{array}{l}\text { Mean cr. } \\
\text { length } \\
(\mathrm{mm})\end{array}$ \\
\hline 37 & 1 & 6 & 8 & 45 \\
47 & 1 & 6 & 24 & 72 \\
50 & 1 & 5 & 33 & 82 \\
52 & 2 & $5 / 4$ & 37 & 85 \\
53 & 2 & $5 / 5$ & 40 & 88 \\
55 & 2 & $5 / 4$ & 44 & 90 \\
56 & 2 & $5 / 4$ & 46 & 92 \\
60 & 1 & 4 & 60 & 100 \\
64 & 1 & 3 & 107 & 120 \\
\hline
\end{tabular}

tions (Dulon et al., 1990). After removing the stria vascularis and the tectorial membrane, the different turns of the organ of Corti were separated from the spiral lamina with a fine forcept. This dissection was carried out under a dissecting microscope at magnification 180 to 250 in tissue-culture medium. Different strips of organ of Corti were isolated and separated in two groups referring to their location along the cochlear spiral: the base (high frequency coding region) for the lower turns, and the apex (low frequency coding region) for the apical turns. The dissected strips were transferred into a $50 \mu \mathrm{l}$ droplet of collagenase medium (type IV from Sigma, $0.5 \mathrm{mg} / \mathrm{ml}$ ) on the middle of a glass coverslide, sealed in the middle of a perforated Petri-dish (Falcon, $55 \mathrm{~mm}$ in diameter). After 15-20 min incubation at room temperature in a humid chamber, the dissociation procedure was completed by gentle flux and efflux of the tissue pieces through a micropipette in the droplet. A resting period of $20 \mathrm{~min}$ allowed the cells to settle down on the glass coverslide, then, cells were carefully rinsed with collagenase-free culture medium. Both isolation procedure and experiments were performed in Hanks balanced salt solution (HBSS, buffered to $\mathrm{pH} 7.4$ with $5 \mathrm{mM}$ Hepes, and adjusted to an osmolarity of $300 \pm 2$ mosm with $\mathrm{NaCl}$ ).

\section{Electrical stimulation of the hair cells: 'Fast motility'}

For the intracellular electrical stimulation, glass micropipettes were filled with $0.1 \mathrm{M}-\mathrm{KCl}, 10 \mathrm{mM}$-sodium Hepes, pH 7.2 (resistances ranging between 80 and 100 $\mathrm{M} \Omega$ ) and were fixed to a stepping micromanipulator (Leitz) for the impalement of the cells. Constant current (square pulse) between $500 \mathrm{pA}$ and $1 \mathrm{nA}$ was injected through a micropipette using a current generator (Microiontophoresis Current Programmer, World Precision Instruments, Sarasota, FL) at a rate of $1 \mathrm{~Hz}$, reversing polarity to avoid membrane charging. Cellular response to positive hyperpolarizing current was an elongation, negative current induced a contraction of 


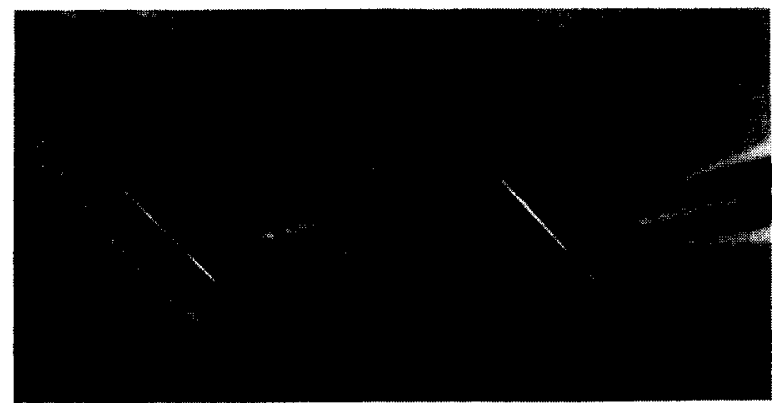

Fig. 1. Electrically-induced motility. Isolated $\mathrm{OHC}$ from the basal coil of a $52 \mathrm{gd}$ guinea-pig cochlea. At resting stage (left) the cell length is $21.8 \mu \mathrm{m}$. When a $1 \mathrm{nA}$ current is injected into the cell through the micropipette, the cell contracts (right), its length is now $20.6 \mu \mathrm{m}$.

cell length. Cycles of movement were measured by frame-by-frame analysis of video recordings. Only cells whose motility followed the stimulus were considered responsive.

\section{Ionomycin induced calcium-stimulation: 'Slow motility'}

As previously described (Dulon et al., 90), the Caionophore ionomycin increases intracellular $\mathrm{Ca}^{2+}$ in $\mathrm{OHC}$ and produces cortical contractions (Dulon et al., 1990). This stimulation was used to test the presence of the $\mathrm{Ca}^{2+}$-induced slow motile property of guinea-pig fetus hair cells. Ten mM stock solutions of ionomycin (from Calbiochem, La Jolla, CA) were prepared in DMSO. The ionophores were added to the cells with a micropipette to yield a final concentration of $10 \mu \mathrm{M}$ (final concentration of DMSO, $0.1 \%$ ). Intracellular calcium was monitored by fluorescence microscopy using the $\mathrm{Ca}^{2+}$ probe Fluo-3 as previously described (Dulon et al., 1990). For dye loading, hair cells were incubated for $30 \mathrm{~min}$ at room temperature $\left(22-25^{\circ} \mathrm{C}\right)$ with Fluo3 /AM diluted in HBSS to a final concentration of $2 \mu \mathrm{M}$. The cells were maintained in a $50 \mu 1$ droplet of HBSS on glass cover slips (thickness, $0.13 \mathrm{~mm}$ ) in a saturated humid chamber (to prevent evaporation and changes in osmolarity of the medium) and subsequently carefully rinsed with HBSS.

Cells loaded with Fluo-3 were observed with an inverted microscope (Leitz Fluovert) fitted with an epifluorescence system (ArcLamp HBO $100 \mathrm{~W}$; a 450$490 \mathrm{~nm}$ band pass exciter filter, $510 \mathrm{~nm}$ dichroic mirror
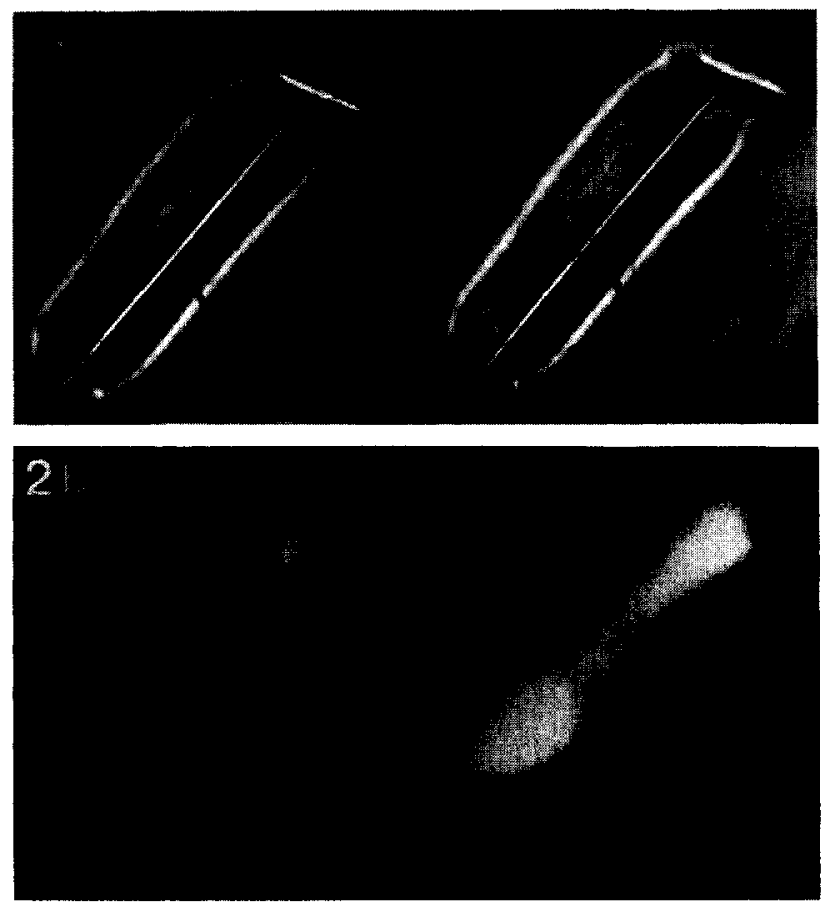

Fig. 2. Calcium-induced motility. Isolated OHC's from the apical coils of $55 \mathrm{gd} \mathrm{(a)} \mathrm{and} 56 \mathrm{gd}$ (b) guinea-pig cochleae. The initial stage (left) is taken after Fluo-3 dye loading. The elongated stage (right), after $30 \mathrm{sec}$ application of ionomycin $(10 \mu \mathrm{M})$. (a): The cell elongation (46.4 to $48.8 \mu \mathrm{m}$ ); (b): the strong $\mathrm{Ca}^{2+}$ increase accompanying the cell elongation is observed with epifluorescence microscopy.

and a $520 \mathrm{~nm}$ barrier filter for excitation and emission, respectively) and a Leitz 160/-NPL Fluotar 50/1.00 oil immersion objective. Cell fluorescence was monitored via a Silicon Intensified Target video camera (SIT 66, Dage-MTI Inc., Michigan City, IN) and recorded for analysis on a video cassette recorder (Mitsubishi SuperVHS, model HS-423UR). The recorded images were analyzed with a Quantex QX-7-210 image processing system (Quantex Corp., Sunnyvale, CA). Cell length was measured from digitalized bright field microscopy images before and after the addition of the ionophore. An increase in intracellular calcium had to be observed for a cell to be included in the length measurements.

Transmission (TEM) and scanning (SEM) electron microscopy

Fetuses were perfused (10 min, intracardiac) with buffered glutaraldehyde (3\%) and paraformaldehyde

TABLE II

MOTILE RESPONSES OF OHCS ISOLATED FROM GUINEA-PIG FETUSES

\begin{tabular}{|c|c|c|c|c|}
\hline \multirow{2}{*}{$\begin{array}{l}\text { Age (gd) of } \\
\text { fetuses }\end{array}$} & \multicolumn{2}{|c|}{ Electrically-induced responses (positive/total cells) } & \multicolumn{2}{|c|}{$\mathrm{Ca}^{2+}$-induced responses (positive/total cells) } \\
\hline & base & apex & base & apex \\
\hline $52-53$ & $6 / 9$ & $0 / 5$ & $5 / 7$ & $1 / 4$ \\
\hline $55-56$ & $4 / 5$ & $2 / 5$ & $11 / 11$ & $3 / 9$ \\
\hline $60-64$ & \multicolumn{2}{|c|}{ all tested cells were positive } & \multicolumn{2}{|c|}{ all tested cells were positive } \\
\hline
\end{tabular}




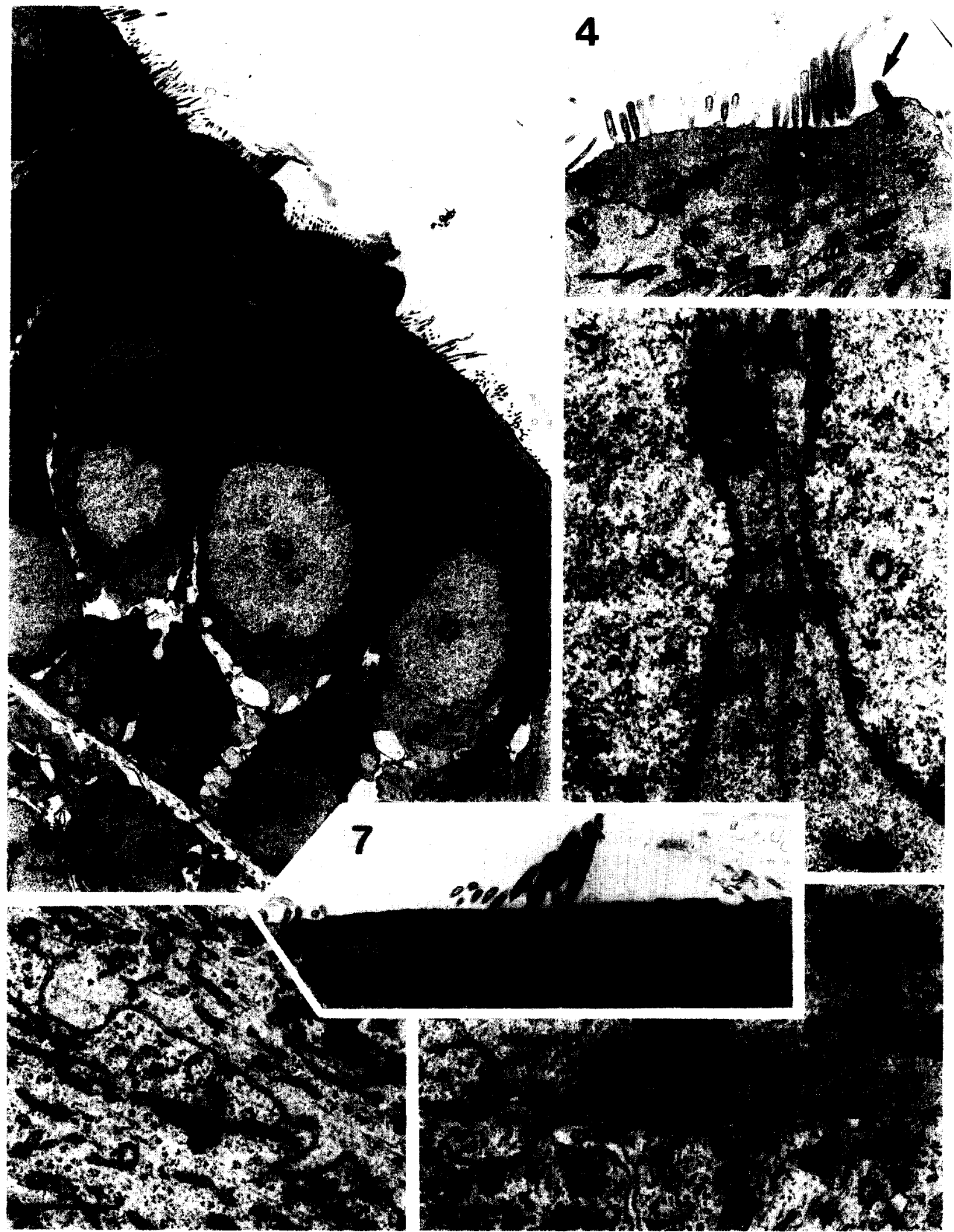


(2\%). The cochleae were dissected out and kept in the same fixative for $1 \mathrm{~h}$, postfixed with osmium (2\% in phosphate buffer), and routinely processed. For TEM, ultra-thin sections were observed using a Jeol 2000 or a Jeol 1200EX electron microscope. At each developmental stage, sections taken randomly from at least 5 basal and 5 apical OHCs were examined. For SEM, specimens were critical point dried, coated with gold and analyzed using an Amray 1000B electron microscope.

\section{Fluorescence histochemistry}

Fetuses were perfused and fixed with $2 \%$ paraformaldehyde in $0.1 \mathrm{M}$ phosphate buffer, $\mathrm{pH} 7.4$. The organ of Corti was immunolabeled with cytokeratin-specific antibodies (monoclonal anti-CK pan, Boehringer Mannheim Biochemicals) and doublelabeled with phalloidin (Molecular Probes) to localize actin. The procedure for labeling was essentially as described by Raphael and Altschuler (1991). Segments (surface preparations) containing half-turns of the organ of Corti were mounted in Gelvatol 20/20 (Monsanto, St. Louis) and photographed using a Leitz Orthoplan microscope.

\section{Results}

\section{Motilities of isolated OHCs (Table II)}

Prior to $50 \mathrm{gd}$, OHCs whatever their location on the cochlear partition could barely be isolated under the standard procedures, even with prolonged incubation in collagenase medium. Dissociation became more successful with advancing gestational age. Cells from the basal turn of embryonic cochleae were easier to harvest than those from apical turns until gd 56. At that time, an equal but still small number of well-preserved basal and apical OHCs could be obtained. In the adult guinea-pig, typically 200-300 cells can be isolated and the yield of apical OHCs far exceeds that of basal OHCs. Beginning at $50 \mathrm{gd}$, cells responded to applied ionomycin with an increase in intracellular calcium but a motile response was not observed.

At 52-53 gd, the electrically-driven fast motility was tested on 14 healthy well dissociated OHCs. Among the basal cells, 6 out of 9 followed the stimulation for several cycles by a contraction-elongation sequence (Fig. 1); they were considered as positive cells. Conversely, none of the 5 apical OHCs tested exhibited a stimulation-following response. However, some of them showed a single and strong contraction, before dying, when the applied current was increased to $1 \mathrm{n} \Lambda$. The $\mathrm{Ca}^{2+}$-induced slow motility was tested on 11 isolated OHCs. Five out of seven OHCs from the basal coil elongated within seconds when applying ionomycin, simultaneously they showed a strong fluorescence increase indicating an increase in their cytoplasmic free calcium. The other 2 cells did not show any response. Only 1 out of 4 apical OHCs tested had a positive motile response with ionomycin. Noteworthy, at this developmental stage, all OHCs either basal or apical are small ( 20 to $30 \mu \mathrm{m}$ in length): the elongation amplitude was 4 to $5 \%$ of the initial length, as found in adult preparations (Dulon et al., 1990).

At $55-56 \mathrm{gd}$, the proportion of positive responses increased in both types of experiments. The electrically-driven motility was observed on 4 out of 5 basal, and on 2 out of 5 apical OHCs. The $\mathrm{Ca}^{2+}$ induced elongation was observed on all of the 11 basal OHCs tested, and on 3 out of 9 apical OHCs (Fig. 2). On positive cells, the elongation amplitude was again in the order of 4 to $5 \%$ of the length.

Figs. 3-6. 37 gd guinea pigs.

Fig. 3. Transverse section at the base of the organ of Corti. OHCs $(\mathrm{O})$ are short $(20 \mu \mathrm{m})$ with a big nucleus. A large number of mitochondria are seen in the supra-nuclear region. A small cuticular plate is just forming; it supports both microvilli and short stereocilia. Deiters cells (D) are small, cuboidal with a thin phalangeal process which separates OHCs from the different rows. Scale bar $=5 \mu \mathrm{m}$.

Fig. 4. Enlargement from the apical pole of the row $1 \mathrm{OHC}$. On this serial section, the beginning of formation of the cuticular plate is better seen. Note the kinocilium (arrow) on the right. Scale bar $=1 \mu \mathrm{m}$.

Fig. 5. More apically, lateral membranes from two adjacent OHCs (rows 1 and 2) are often in direct contact, especially at the nuclear level. Scale bar $=0.5 \mu \mathrm{m}$.

Fig. 6. Cytoplasmic indentations between an $\mathrm{OHC}(\mathrm{O})$ and its neighbouring Deiters cell (D). Scale bar $=1 \mu \mathrm{m}$.

Figs. 7-8. 53 gd guinea pigs.

Fig. 7. The cuticular plate of an $\mathrm{OHC}$ is now thicker and almost devoid of microvilli (compare with Fig. 4). Scale bar $=1 \mu \mathrm{m}$.

Fig. 8. Below the cuticular plate of an $\mathrm{OHC}(\mathrm{O})$, the smooth endoplasmic reticulum is abundant and sometimes it begins to get aligned (arrowheads) along the lateral membrane. D: Deiters cell. Scale bar $=0.5 \mu \mathrm{m}$. 

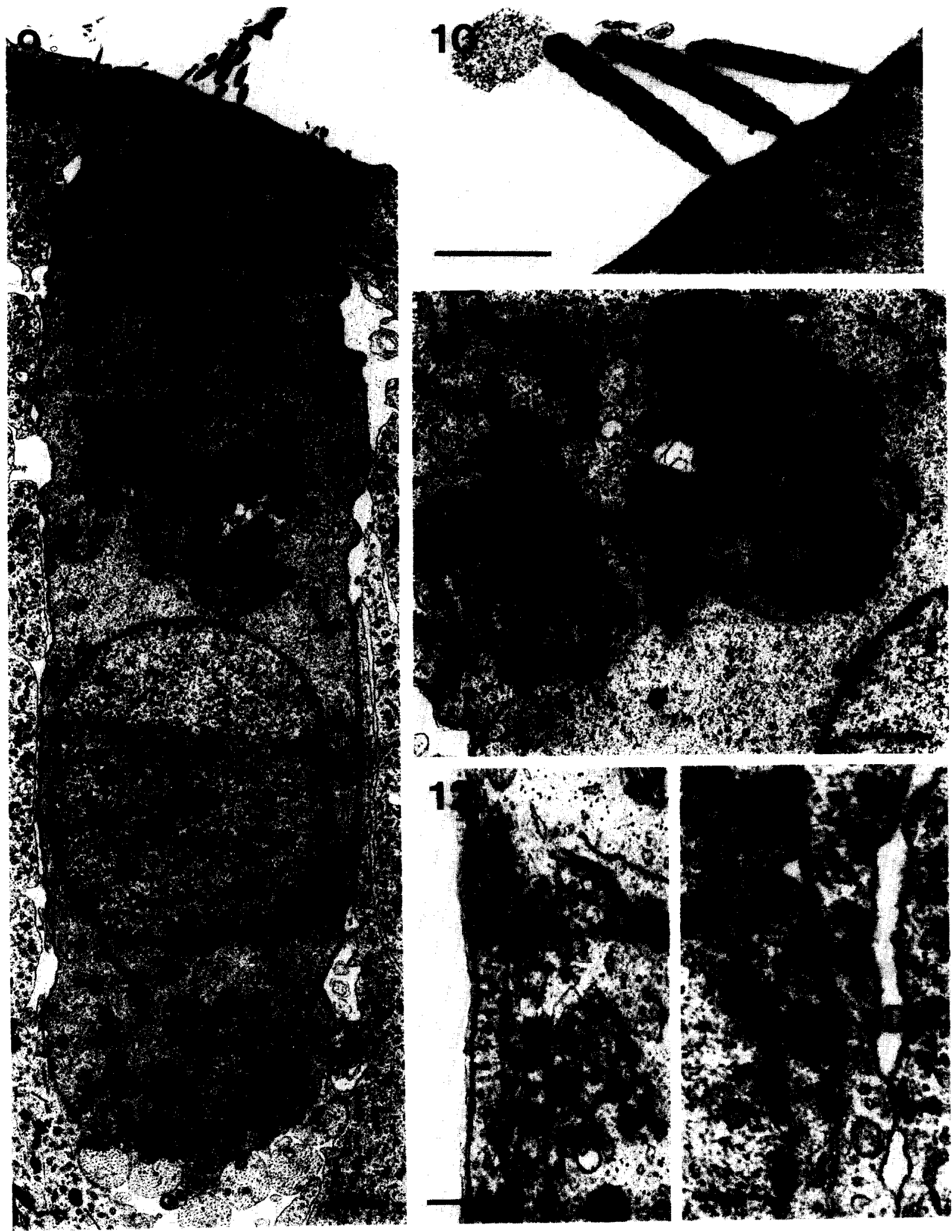

2.

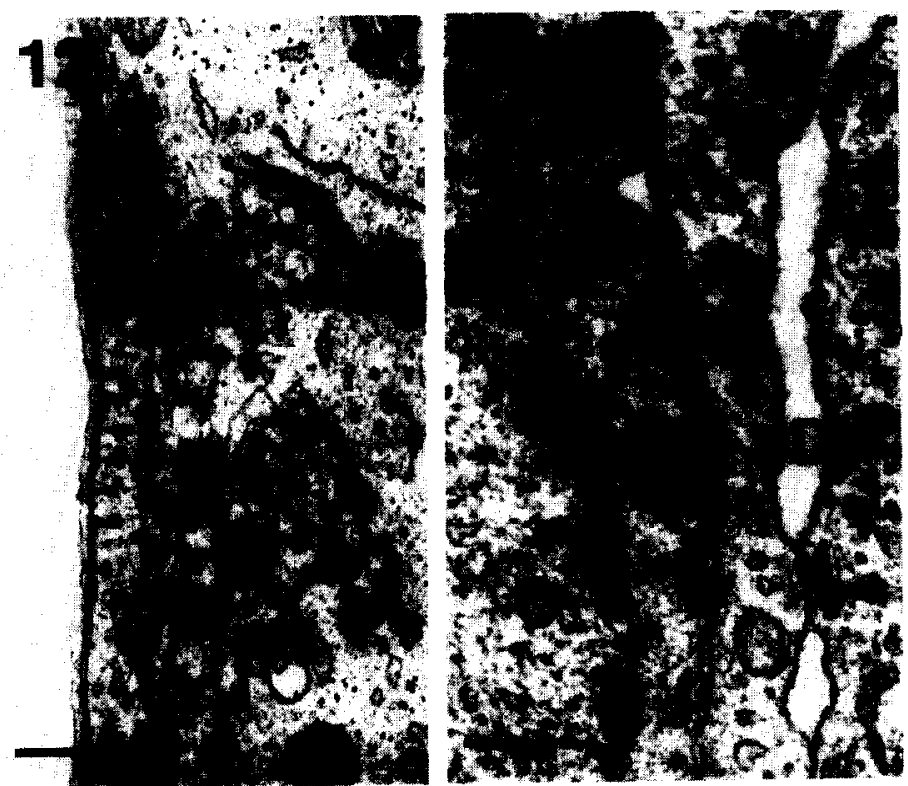


At $64 \mathrm{gd}$, just prior to birth, all tested cells in both basal and apical coils responded positively, either with electrical or ionomycin stimulations.

\section{Morphological correlates}

With regard to the above physiological results, three periods of development were particularly interesting to study: prior to $50 \mathrm{gd}$, when no motile responses were observed; at 52-53 $\mathrm{gd}$, when motile responses appeared in some of the basal OHCs; at $56 \mathrm{gd}$, when almost all basal and some apical OHCs responded. In all cases, the fine morphology of developing OHCs, particularly the structures which are concerned with the motility, was compared to what is found in mature OHCs.

Prior to $50 \mathrm{gd}$. At $37 \mathrm{gd}$, whatever their position on the cochlear spiral, OHCs were clearly immature. Short (about $20 \mu \mathrm{m}$ ), round-shaped, with a basal nucleus, they were closely packed within the supporting elements, leaving no intercellular fluid space (Fig. 3). The supra-nuclear region of the $\mathrm{OHC}$ was rich in mitochondria and a thin cuticular plate was beginning to form, supporting small growing stereocilia and a kinocilium (Fig. 4). The OHC lateral membrane showed no specialization of any sort. The Deiters cells were small, cuboidal and had a thin phalangeal process separating the different rows of OHCs and reaching the luminal surface (Fig. 3). In the most apical and immature regions of the cochlea, this Deiters cell phalangeal process did not completely separate the different rows of OHCs, leaving two adjacent hair cells closely apposed by their lateral membrane, especially in the nuclear region (Fig. 5). Frequently, cytoplasmic indentations were seen tightly attaching hair cell and supporting cell (Fig. 6); desmosomes were also present in the OHC-supporting cell junctions, close to the luminal surface. These features probably accounted for most of the difficulty to isolate OHCs at this developmental stage.

Very few morphological changes were noticed on most of OHCs from $47 \mathrm{gd}$ fetuses. However, in the basal turn, OHCs exhibited two criteria of maturation: 1), the cuticular plate was thicker and almost devoid of small microvilli (Fig. 7) and 2), in the upper region of the lateral plasma membrane, a first sign of formation of a laminated cistern was noticed (Fig. 8).

$52-53 \mathrm{gd}$. As indicated by the gross morphology, the organ of Corti was now entering the last stage of its maturation: i.e., opening of the tunnel and formation of the Nuel's spaces between OHCs. This process was more advanced at the base than at the apex of the cochlea. A basal $\mathrm{OHC}$ was now 20 to $35 \mu \mathrm{m}$ in length (Fig. 9). Its cuticular plate had developed and the roots of stereocilia were visible (Fig. 10); however the kinocilium was still present on the nearby apical surface. The most striking feature concerned the increase in density of mitochondria and of smooth endoplasmic reticulum in the supra-nuclear region, below the cuticular plate (Figs. 9,11). Round-shaped clusters of endoplasmic reticulum were observed closely associated with portions of the reticulum near the lateral plasma membrane (Figs. 9,11,12). Lining the lateral wall of the $\mathrm{OHC}$, the laminated cisternae complex has been formed, with a first layer now almost completed. At this stage, the distance between the plasma membrane and the first layer of cisternae was irregular and greater than in adult specimens; neither pillars nor sub-plasma membranc could bc clearly discerned in between. The formation of the laminated cistern proceeded from the luminal surface to the synaptic pole of the OHC. In a given cell, at this stage, the process is much more advanced apically (Fig. 12) than at nuclear level (Fig. 13) where the first layer is not continuous.

SEM analysis revealed a surface maturation of the guinea-pig organ of Corti which mimics what has been described for the rat pup (Lenoir et al., 1987). Therefore, results are not shown but for stage $52 \mathrm{gd}$, when the OHC motility begins. At this stage, specimens revealed the base to apex gradient of maturation in the surface of the organ of Corti (Figs. 14a,b). Apical $\mathrm{OHCs}$ were irregularly arranged, especially those of second and third rows (Fig. 14a). In contrast, OHCs at

Figs. 9-13. 53 gd guinea pigs.

Fig. 9. Basal $\mathrm{OHC}$ at the onset of in vitro motilities. As compared with Fig. 3 ( $37 \mathrm{gd}$ ), the OHC is taller ( $27 \mu \mathrm{m})$ and more cylindrical in shape. The cuticular plate and stereocilia are about mature (see also Fig. 10). In the supra-nuclear region, the cytoplasm contains an exhuberant endoplasmic reticulum, sometimes forming round-shaped clusters (see also Fig. 11). A first layer of laminated cisternae is formed (best seen in

Fig. 12). Scale bar $=1 \mu \mathrm{m}$.

Fig. 10. OHC stereocilia: note the staircase arrangement and the roots deeply implanted into the cuticular plate. Scale bar $=1 \mu \mathrm{m}$.

Fig. 11. Clusters of endoplasmic reticulum in the supra-nuclear cytoplasm of an OHC. Note the relationships between this reticulum (arrows) and the first layer of laminated cisternae (arrowheads). Scale bar $=1 \mu \mathrm{m}$.

Fig. 12. Regular alignment of the first cistern (arrowheads) along the plasma membrane in the apical region of an $\mathrm{OHC}$. Scale bar $=1 \mu \mathrm{m}$.

Fig. 13. Irregular and incomplete cistern (arrows) in the nuclear region of an $\mathrm{OHC}$. Scale bar $=0.5 \mu \mathrm{m}$. 

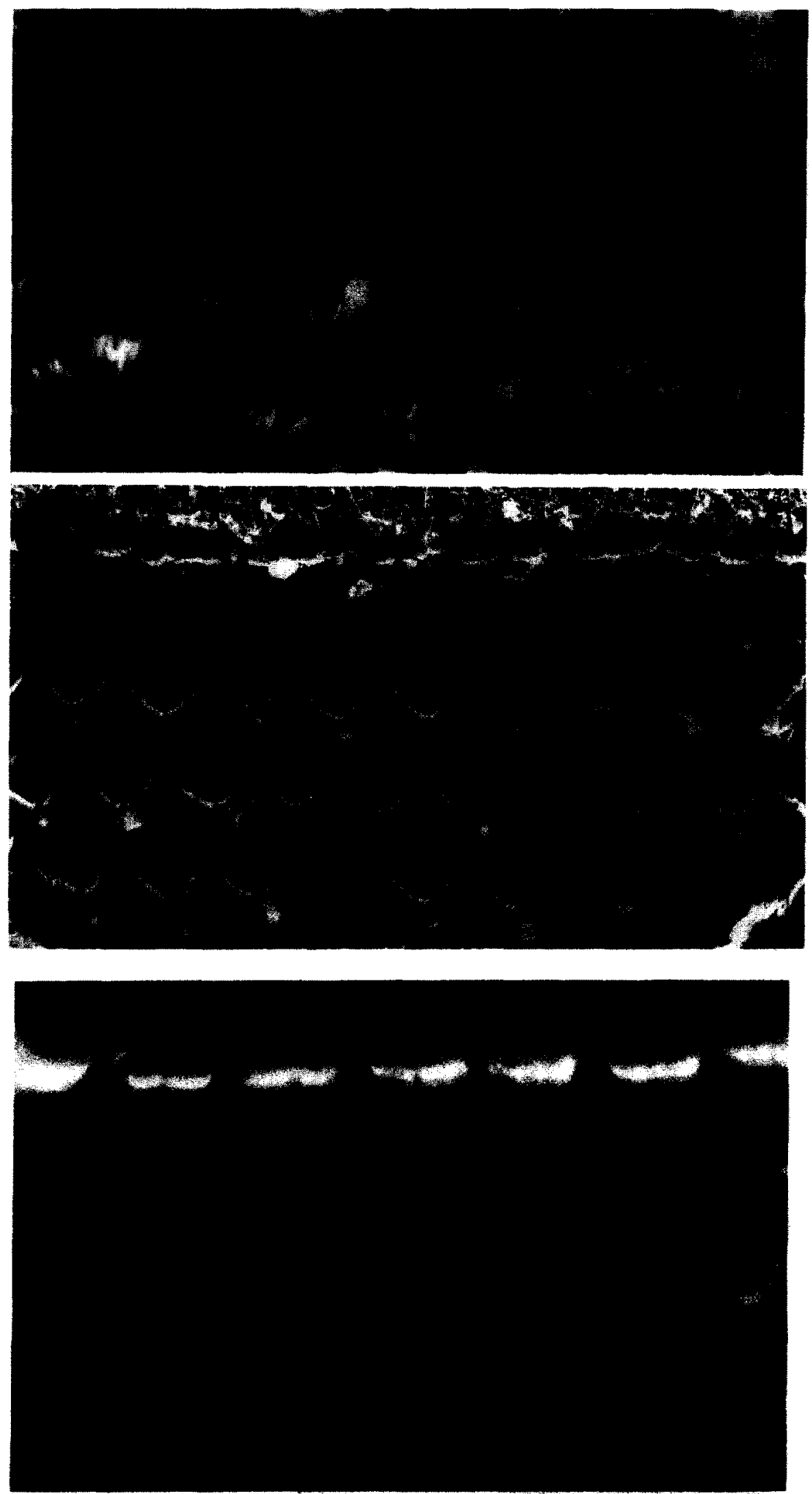

Fig. 14. Apical (A) and basal (B) scanning electron microscopic views from the surface of a $52 \mathrm{gd}$ organ of Corti (at time of onset of motility in base). Note the base-to-apex gradient of maturation: mainly characterized by the more regular pattern of hair cell arrangement in $B$.

Fig. 15. Basal region of the cochlea from a $52 \mathrm{gd}$ guinea-pig (onset of in vitro motilities). The distribution of actin showed with fluorescein phalloidin restricted in the reticular lamina, and stereocilia bundle is almost mature. 
the base of the cochlea were regularly arranged and their surface appeared mature apart from the presence of a kinocilium (Fig. 14b). In both cases, pillar cells and Deiters cells were covered with numerous small microvilli (Figs. 14a,b). The distribution of actin in the apical domain of the $\mathrm{OHC}$ was similar to the mature stage, with intense labeling in the cuticular plate and stereocilia (Fig.15). Conversely, from 50 gd on, cytokeratin immunoreactivity was no longer detected in hair cells, but only in supporting cells.

$56 \mathrm{gd}$. Within the next few days, the maturational processes reported above have quickly progressed. At $56 \mathrm{gd}$, the tunnel of Corti was completely open and Nuel's spaces had an adult-like appearance. Basal OHCs had reached their definitive length: $(40 \mu \mathrm{m}$, in the upper basal turn, Fig. 16). Their cuticular plate had now a mature appearance and stereocilia also bore adult characteristics: a staircase arrangement, crosslinks, tip-links and roots deeply implanted in the electron-dense material of the cuticular plate (Fig. 17). Within the supra-nuclear region of the cytoplasm, the intense production of reticular membranes was still obvious (Fig. 16). On the opposite pole of the OHC, another indication for maturity was the appearance of dense intercellular material at the basal junction between the $\mathrm{OHC}$ and the Deiters cell. On the Deiters side of that junction numerous microtubules were noticed (Fig. 18). The laminated cisternae complex was composed of a first layer very regularly apposed to the plasma membrane. This first layer extended now from the cuticular plate down to the synaptic pole of the OHC. Second or third layers were irregularly scattered in several locations (Figs. 19, 20). Between the plasma membrane and the first layer of cisternae, the subplasma membrane material such as pillars were distinguishable (Fig. 20). OHCs from apical turns had also matured, approaching an adult length (60 to $70 \mu \mathrm{m}$ ). Their cuticular plate, stereocilia, and lateral membrane were very similar to basal OHCs at this stage.

$60-64 \mathrm{gd}$. The organ of Corti had largely completed its development, as judged by gross morphology and ultrastructure. OHCs and supporting Deiters cells showed an adult-like ultrastructural aspect.

\section{Discussion}

\section{OHC motile responses: Fetal versus adult data}

The difficulty in isolating OHCs from the youngest fetuses used in this study is due to the overall immaturity of the organ of Corti, as determined by TEM, SEM and molecular analysis of the cytoskeleton. The lack of extracellular fluid spaces, and the extensive junctions OHCs have with the surrounding cells at this stage, are particularly significant in that respect. Once OHCs were isolated from fetal cochleae (around $50 \mathrm{gd}$ ), they could be loaded with the fluorescent calcium indicator Fluo-3 by incubation with its membranc permeant ester, Fluo-3/AM. This indicated the presence of active intracellular esterases and the integrity of the plasma membrane of the fetal isolated hair cells, as previously described for mature OHC (Dulon et al., 1989, 1990).

Prior to $52 \mathrm{gd}$, all hair cells (basal and apical) did not show any sign of cortical contraction (elongation), when increasing their $\left[\mathrm{Ca}^{2+}\right] i$ under ionomycin stimulation. This indicated that at this stage of development the OHCs do not possess a functional contractile apparatus. In some aspect, they behaved more like IHCs, which also fail to respond to calcium stimulation (Dulon et al., 1991). The appearance of the $\mathrm{Ca}^{2+}$-induced motility under ionomycin stimulation occurred first in basal, then a few days later in apical OHCs. An obvious potential criticism arises, as most of basal $\mathrm{OHCs}$ from 52-53 gd fetal cochleae are positive, while no clear response was noticed at earlier stages when isolation was difficult. Prior to $52 \mathrm{gd}$, some $\mathrm{OHCs}$ might have responded positively if we could have isolated more of them. On the contrary, the date of appearance of the $\mathrm{Ca}^{2+}$ driven motility in apical OHCs is less ambiguous, as only a third of OHCs are positive at 55-56 gd, a time when isolating hair cells is no longer a problem. Once present, the amplitude and time course of these cortical contractions (elongations) were rather similar to those observed previously in mature $\mathrm{OHCs}$ (Dulon et al., 1990).

Responses to electrical stimulation followed the same pattern of appearance of the $\mathrm{Ca}^{2+}$-contractions. They appeared at 52-53 gd for basal OHCs and at 55-56 gd for apical OHCs. Although the OHC ability to follow current stimulation at high frequencies was not tested, these electrically-induced motile responses might reflect the first appearance, during development, of the cochlear amplifier (Ashmore, 1987; Zenner et al., 1987).

\section{Development of motile responses as part of the overall cochlear maturation}

Our results indicate that a critical stage of the $\mathrm{OHC}$ development occurs in the guinea-pig cochlea between 50 and 60 days of pregnancy. This is the period when isolated OHCs begin to show and develop two types of motile responses, an electrically-driven and $\mathrm{a} \mathrm{Ca}^{2+}$-induced response. In the meantime, the morphology of $\mathrm{OHCs}$ changes drastically as these cells acquire ultrastructural and immunocytochemical adult-like characteristics.

Despite the common use of the guinea-pig for experimental studies of the cochlear physiology, few data are available concerning the cochlear development in this species. However, a general schedule of the matu- 
ration can be proposed. The onset of cochlear function occurs around $52-53 \mathrm{gd}$, as indicated by recording gross cochlear potentials (Romand, 1971; Romand et al., 1971; Pujol and Hilding, 1982). The main events of structural maturation and synaptogenesis have also been reported to occur between $45 \mathrm{gd}$ and birth, (Thorn, 1975; Pujol and Hilding, 1982). At birth, a mature cochlea is found. It is of interest to correlate
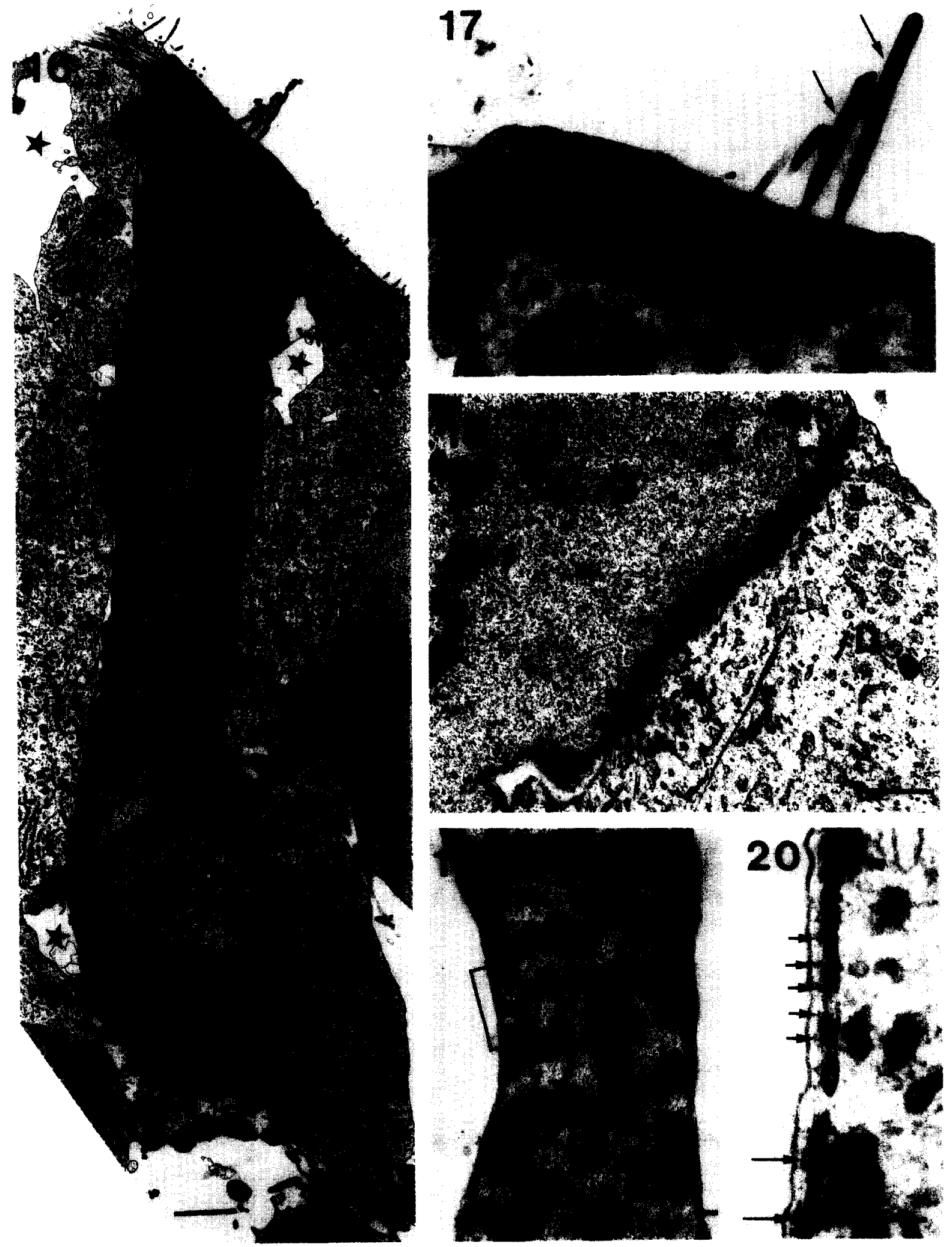
the maturation of OHCs motilities with that of tuning curves or oto-acoustic emissions, features which are thought to be associated with the active bio-mechanism. In the absence of data from guinea-pig, correlations can be made using the rat for which such data have been published (Carlier et al., 1979; Puel and Uziel, 1987; Lenoir and Puel, 1987; Norton et al., 1991). Thus, taking into account the available developmental criteria, is it possible to consider that a guineapig at $52 \mathrm{gd}$ (at the time of onset of cochlear function) corresponds to a 10-day-old rat pup, and a guinea-pig at birth corresponds to a 20- to 25-day-old rat pup (see also the comparative Table in Pujol and Hilding, 1973). At this later stage in the rat, both the compound action potential tuning curves (Puel and Uziel, 1987) and the distortion product emissions (Lenoir and Puel, 1987) are almost mature, and this is also probably true in the newborn guinea-pig. This correlates quite well with our finding of adult-like motile properties of OHCs isolated from guinea-pigs at $60 \mathrm{gd}$ and over.

It is noteworthy that the appearance and development of OHC motilities in vitro follows a base-to-apex gradient similar to maturation in vivo. This, together with the good timing coincidence discussed above, strongly supports the idea that motile properties of OHCs observed in vitro reflect the in vivo active mechanisms.

\section{Structural corrrelates}

Physiological and anatomical studies were performed on separated littermates and, obviously, not on the same cells. Then, even if particular attention was made to work on littermates having the same gross developmental aspects (same weight and size), and to select OHCs from similar levels of the cochlea, one cannot exclude differences in the maturation of fetuses and/or differences in the maturation of OHCs belonging to slightly different levels of the cochlea.

During the early stages (37-47 gd) the immaturity of the organ of Corti as a whole is obvious,: hair cells and supporting cells being densely packaged, with no fluid spaces in between. Moreover, the difficulty of separat- ing the OHCs probably increases because of the particularly tight OHC-Deiters cell junction at this stage. Especially, close to the luminal surface both the OHCs and the Deiters cells are tightly linked by desmosomes and cytoplasmic indentations. These features regress and totally disappear by $50 \mathrm{gd}$. In the meantime, spaces of Nuel are forming: they are clearly differentiated at $52 \mathrm{dp}$, a stage when $\mathrm{OHC}$ isolation becomes much easier. Prior to the onset of motility, OHCs acquire an adult-like distribution of microfilaments and intermediate filaments. The finding that cytokeratin-specific immunoreactivity disappeared from OHCs at this stage is consistent with earlier results on down regulation during development (Raphael et al., 1987) and may suggest that the presence of these rigid and stable proteins is incompatible with motility, and related functions of OHCs. Actin is present in conspicuous amount in stereocilia, cuticular plate and adherens junctions of mature OHCs; it may also be present in small quantities in association to the lateral wall of OHCs (Thorne et al., 1987; Slepecky et al., 1988). Actin starts to accumulate in the cuticular plate and stereocilia more than a week prior to the onset of motility, but further studies are needed to conclusively determine its distribution along the lateral wall of developing $\mathrm{OHCs}$, and its relation to the development of the calcium-induced motility.

The onset of motility in isolated guinea-pig OHCs ( 52 to $56 \mathrm{gd}$ ) coincides, at gross morphological level, with an increase in the length of the cell, which also attains its size (length and diameter) and its very regular cylindrical shape. However, the most prominent ultrastructural $\mathrm{OHC}$ changes are at the level of the subsurface cisternae complex. Namely, a first layer of laminated cisternae is differentiated, although it does not bear yet its mature appearance. Incidently, our results point out the strong relationship existing between the clusters of endoplasmic reticulum, strikingly abundant at this stage in the supra-nuclear region of the cytoplasm, and the cisternae (see also, Thorn, 1975). Such an abundance of smooth endoplasmic reticulum has already been found in OHCs under

Figs. 16-20. 56 gd guinea pigs.

Fig. 16. Upper basal $\mathrm{OHC}$ showing an almost mature morphology, except for its lateral contact with phalangeal processes of Deiters cell (D), as spaces of Nuel (stars) are not completely formed. Scale bar $=2 \mu \mathrm{m}$.

Fig. 17. Cuticular plate from a basal OHC. Mature appearance of the stereocilia with cross (arrowheads) and tips (thin arrows) links. Scale bar $=1 \mu \mathrm{m}$.

Fig. 18. Basal junction between an $\mathrm{OHC}(\mathrm{O})$ and a Deiters cell (D). Note the dense material at the junction and microtubules (arrows) on the Deiters cell. Scale bar $=1 \mu \mathrm{m}$.

Fig. 19-20. Basal OHC: supranuclear region. The laminated cisternae complex is now well formed, with sometimes a second and third layer (arrowheads). Between the first layer and the plasma membrane, pillars (short arrows) and other filamentous material (tall arrows) are clearly seen. Scale bar $=0.2 \mu \mathrm{m}$. 
different pathologic situations, such as acoustic trauma where the clusters have been called Hensen bodies (Spoendlin, 1970; Dodson et al., 1982) or lamellar bodies (Saito, 1983). A possible explanation for finding these formations in pathological cases would be a restoration process of an injured cisternae complex.

In adults, the laminated, or subsurface cisternae complex (Engström, 1967; Saito, 1983) may have a role in both 'fast' and 'slow' motile responses. The fast motility either conceived as an electro-osmotic (Kachar et al., 1986), an electrostrictive (Ashmore, 1987), or a displacement generator mechanism (Dallos et al., 1991) needs the linear arrangement of cisternae along the plasma membrane for the generation of longitudinal forces. Furthermore, recent observations suggest that the electrically-driven motility is indeed related to ultrastructural changes in cisternae (Evans, 1990). More precisely, the contractile apparatus is supposed to be located in the sub-plasma cortical system interposed between the plasma membrane and the first layer of cisternae (Holley and Ashmore, 1989; 1990). It has also been proposed that in slow motility the laminated cistenae could play a role in storing and releasing $\mathrm{Ca}^{2+}$, as the T-tubules in muscles (Flock et al., 1986) acting on a cortical contractile apparatus associated with the cell membrane along the $\mathrm{OHC}$ lateral wall (Slepecky, 1989; Ulfendahl and Slepecky, 1988).

The cisternal complex, at onset of motility, corresponds to a regular alignment of one layer of cistern along the lateral plasma membrane, although this formation is not yet completely down to the base. This tends to indicate that if cisternae are involved in motility, it is not the number but only the first layer that is critical. A similar conclusion can be drawn by comparing, at adult stage, the differences in number of cisternae among OHCs from different species or different turns in a same species: there is no logical correlation between this number and the respective physiology of OHCs; this has been already suggested (Spoendlin, 1966) and discussed (Ekström von Lubitz, 1981). Actually, both the horseshoe bat (Vater et al., 1991) and the mole-rat (Raphael et al., 1991) OHCs have a single layer of cisternae: yet, the former with their specialization to ultra-high frequencies should have more powerful active mechanisms than the latter which is only concerned with low frequencies. If the cisternal complex is to account for the physiological differences presumed to be based upon OHC motilities, the critical feature is not the number of cisternac but more likely the organization of the first layer and attached lattice (Holley and Ashmore, 1990; Forge, 1991; Dieler et al., 1991). Moreover, as already proposed (Evans, 1990; Holley and Ashmore, 1990; Dallos et al., 1991), only the apparatus above the nucleus may be important for motility.

The onset of motility also coincided with the forma- tion of the arms (Raphael and Wroblewski, 1986) or pillars (Flock et al., 1986; Bannister et al., 1988; Lim et al., 1989; Arnold and Anniko, 1990), stuctures which link the plasma membrane to the outermost layer of cisternae. More precisely the pillars seem to be attached to a fibrillar meshwork on the outer surface of the first cisternal membrane (Forge, 1991). This subplasmalemmal filamentous material (among others: Gulley and Reese, 1977; Saito, 1983; Lim, 1986, Ulfendahl and Slepecky, 1988) is thought to be composed of the cortical lattice (Holley and Ashmore, 90) and is probably involved in the two types of motility (Slepecky, 1989; Holley and Ashmore, 1990; Dulon et al., 1990). The formation and development of this lattice and pillars, probably account for setting the motile responses of fetal $\mathrm{OHCs}$ at an adult-like appearance. However, the present data limited to classical TEM do not bring enough information on this point and further analyses using freeze-fracture or freezeetching (Forge, 1991) are needed.

\section{Acknowledgements}

This work was supported by program project grant DC-00078 from N.I.H. Thanks are due to C. Sheridan, J. Horn, C. Ripoll, F. Tribillac and P. Sibleyras for expert technical assistance.

\section{References}

Arnold, W. and Anniko, M. (1990) Structurally-based new functional interpretations of the subsurface cisternal network in human outer hair cells. Acta Otolaryngol. (Stockh.) 109, 213-220.

Ashmore, J.F. (1987) A fast motile response in guinea-pig outer hair cells: The cellular basis of the cochlear amplifier. J. Physiol. (London) $388,323-347$.

Bannister, L.H., Dodson, H.C. Astbury, A.R, and Douek, E.E. (1988) The cortical lattice: a highly ordered system of subsurface filaments in guinea pig cochlear outer hair cells. Prog. Brain Res. 74, 213-219.

Brownell, W.E. (1984) Microscopic observation of cochlear hair cell motility. Scanning Electr. Microsc. III, 1401-1406.

Brownell. W.E., Bader, C.R., Bertrand, D. and de Ribaupierre, Y. (1985) Evoked mechanical responses in isolated cochlear outer hair cells. Science 227, 194-196.

Carlier. E., Lenoir, M. and Pujol, R. (1979) Development of cochlear frequency selectivity tested by compound action potential curves. Hear. Res. 1, 197-201

Dallos, P., Evans B.N. and Hallworth, R. (1991) Nature of the motor element in electrokinetic shape changes of cochlear outer hair cells. Nature (Lond.) 350, 155-157.

Dieler, R., Shehata-Dieler W.E. and Brownell, W.E. (1991) Concomitant salicylate-indured alterations of outer hair cell subsurface cisternae and electromotility. J. Neurocytol. (in press).

Dodson, H.C., Bannister. L.H. and Douek, E.E. (1982) The effects of combined gentamicin and white noise on the spiral organ of young guinea pigs. Acta Otolaryngol. (Stockh.) 94, 193-202.

Draper, R.L. (1920) The prenatal growth of the guinea-pig. Anat. Rec. 18, 369-392. 
Dulon, D., Zajic, G. and Schacht, J. (1988) [K+]-depolarization induces motility in outer hair cells by an osmotic mechanism. Hear. Res. 32, 123-130.

Dulon, D., Zajic, G. and Schacht, J. (1990) Increasing intracellular free calcium induces circumferential contractions in isolated cochlear outer hair cells. J. Neurosci. 10, 1388-1397.

Dulon, D., Zajic, G. and Schacht, J. (1991) Differential motile response of isolated inner and outer hair cells to stimulation by potassium and calcium. Hear. Kes. 52, 225-232.

Dulon, D., Zajic, G., Aran, J.-M. and Schacht, J. (1989) Photo-induced irreversible shortening and swelling of isolated cochlear outer hair cells. Int. J. Radiat. Biol. 55, 1007-1014.

Ekström von Lubitz, D.K.J. (1981) Subsurface tubular system in the outer sensory cells of the rat cochlea. Cell Tissue Res. 220, 787-795.

Engström, H. (1967) The ultrastructure of the sensory cells of the cochlea. J. Laryngol. Otol. 81, 687-715.

Evans, B.N. (1990) Fatal contractions: ultrastructural and electromechanical changes in outer hair cells following transmembraneous electrical stimulation. Hear. Res. 45, 265-282.

Flock, A., Flock, B. and Ulfendahl, M. (1986) Mechanisms and movement in outer hair cells and a possible structural basis. Arch. Otorhinolaryngol. 243, 83-90.

Forge, A. (1991) Structural features of the lateral walls in mammalian cochlear outer hair cells. Cell Tiss. Res. (in press).

Gulley, R.L. and Reese, T.S. (1977) Regional specialization of the hair cell plasmalemma in the organ of Corti. Anatomical Record, $189,109-124$.

Holley, M.C. and Ashmore, J.F. (1988) A cytoskeletal spring in cochlear outer hair cells. Nature 335, 635-637.

Holley, M.C. and Ashmore, J.F. (1988) On the mechanism of highfrequency force generator in outer hair cells isolated from the guinea pig cochlea. Proc. R. Soc. Lond. B 232, 413-429.

Holley, M.C. and Ashmore, J.F. (1990) Spectrin, actin and the structure of the corlical lattice in mammalian cochlear outer hair cells. J. Cell Sci. 96, 283-291.

Kachar, B., Brownell, W.E., Altschuler, R. and Fex, J. (1986) Electrokinetic shape changes of cochlear outer hair cells. Nature 322 , 365-367.

Kemp, D.T. (1978) Stimulated acoustic emissions from the human auditory system. J. Acoust. Soc. Am. 64, 1386-1391.

Lenoir, M. and Puel, J.-L. (1987) Development of $2 f_{1}-f_{2}$ otoacoustic emissions in the rat. Hear. Res. 29, 265-271.

Lenoir, M., Puel, J.L. and Pujol, R. (1987) SEM study of the rat cochlear development with an emphasis on strereocilia and tectorial membrane. Anat. Embryol. 175, 477-487.

Lim, D.J. (1986) Functional structure of the organ of Corti: A review. Hear. Res. 22, 117-146.

Lim, D.J., Hanamure, Y. and Ohashi, Y. (1989) Structural organization of the outer hair cell wall. Acta Otolaryngol. (Stockh.) 107, $398-405$.

Norton, S.J., Bargones, J.Y. and Rubel, E.W. (1991) Development of otoacoustic emissions in gerbil: evidence for micromechanical changes underlying development of the place code. Hear. Res. 51 73-92.

Puel, J.-L. and Uziel, A. (1987) Currelative development of cochlear action potential sensitivity, latency, and frequency selectivity. Dev. Brain Res. 37, 179-188.

Pujol, R. (1986) Synaptic plasticity in the developing cochlea. In: R.W. Ruben, T.R. Van de Water and E.W. Rubel (Eds.), The Biology of Change in Otolaryngology, Elsevier Science Publishers B.V. (Biomedical Division), New York, pp. 47-54.

Pujol, R. (1989) Anatomie et physiologie de la cochlée. Arch. Int. Physiol. Bioch. 97-4, A51-A78.

Pujol, R. and Hilding, D.A. (1973) Anatomy and physiology of the onset of auditory function. Acta Otolaryngol. (Stockh.) 76, 1-10.

Pujol, R., Carlier, E. and Lenoir, M. (1980) Ontogenetic approach to inner and outer hair cells functions. Hear. Res. 2, 423-430.
Pujol, R., Zajic, G., Dulon, D., Altschuler, R.A. and Schacht, J. (1990a) First appearance and development of slow and fast motile responses of outer hair cells. Abstr. Assoc. Res. Otolaryngol. St. Petersburg, FL, p. 247.

Pujol, R., Zajic, G., Dulon, D., Altschuler, R.A., Raphael, Y. and Schacht, J. (1990b) Development of in vitro fast and slow motilities of outer hair cells: structural correlates. Abstr. 27th Workshop Inner Ear Biology, Stockholm.

Raphael, Y. and Wroblewski, R. (1986) Linkage of sub-membranecisterns with the cytoskeleton and the plasma membrane in cochlear outer hair cells. J. Submicrosc. Cytol. 18, 731-737.

Raphael, Y. and Altschuler, R.A. (1991) Reorganization of cytoskeletal and junctional proteins durin cochlear hair cell degeneration. Cell Motil. Cytoskeleton 18,

Raphael, Y., Marshak, G., Barash, A. and Geiger, B. (1987) Modulation of intermediate filament expression in the developing cochlear epithelium. Differentiation 35, 151-162.

Raphael, Y., Lenoir, M., Wroblewski, R. and Pujol, R. (1991) The sensory epithelium and its innervation in the mole rat cochlea. $J$. Comp. Neurol. (in press).

Romand, R. (1971) Maturation des potentiels cochléaires dans la période périnatale chez le Chat et chez le Cobaye. J. Phys. 63, $763-782$.

Romand, R., Granier, M.-R. and Pujol, R. (1971) Potentiels cochléaires chez le Cobaye dans la période prénatale. J. Phys. 63, 280-281 A.

Saito, K. (1983) Finc structure of the sensory cpithclium of guinea-pig organ of Corti: subsurface cisternae and lamellar bodies in the outer hair cells. Cell Tissue Res. 229, 467 -481.

Santos-Sacchi, J. (1988) Cochlear physiology. In: A.F. Jahn and J. Santos-Sacchi (Eds.) Physiology of the ear, Raven Press, New York, pp. 271-29.3.

Slepecky, N. (1989) Cytoplasmic actin and cochlear outer hair cell motility. Cell Tissue Res. 257, 69-75.

Slepecky, N., Ulfendahl, M., Flock, A. (1988) Effects of caffeine and tetracaine on outer hair cell shortening suggest intracellular calcium involvement. Hear. Res. 32, 11-22.

Spoendlin, H. (1966) The organisation of the cochlear receptor. In: L. Rüedi (Ed.), Adv. Oto-Rhino-Laryngol. 13, Karger, Basel, New York.

Spoendlin, H. (1970) Auditory, vestibular, olfactory and gustatory organs. In: J. Babel, A. Bischoff and H. Spoendlin (Eds.), Ultrastructure of the peripheral nervous system and sense organs. Atlas of normal and pathologic anatomy, Georg Thieme Verlag, Stuttgart, pp. 173-338.

Thorn, L. (1975) Die Entwicklung des Cortischen Organs beim Meerschweinchen. Adv. Anat. Embryol. Cell Biol. 51, 1-97.

Thorne, P.R., Carlisle, L. Zajic, G. Schacht, J. and Altschuler, R.A. (1987). Differences in distribution of F-actin in outer hair cells along the organ of Corti. Hear. Res. 30, 253-266.

Ulfendahl, M. and Slepecky, N. (1988) Ultrastructural correlates of inner ear sensory cell shortening. J. Submicrosc. Cytol. Pathol. 20, $47-51$

Vater, M., Lenoir, M. and Pujol, R. (1991) Ultrastructure of the horseshoe bat's organ of Corti. II. Transmission electron microscopy. J. Comp. Neurol, (in press).

Zajic, G. and Schacht, J. (1987) Comparison of isolated outer hair cells from five mammalian species. Hear. Res. 26, 249-256.

Zenner, H.-P. (1986) Motile response in outer hair cells. Hear. Res. 22, $1-14$.

Zenner, H.-P., Zimmermann, U. and Schmitt, U. (1985) Reversible contraction of isolated mammalian cochlear hair cells. Hear. Res. $18,127-133$.

Zenner, H.-P., Zimmermann, U. and Gitter, A.H. (1987) Fast motility of isolated mammalian auditory sensory cells. Biochem. Biophys. Res. Comm. 149, 304-308. 